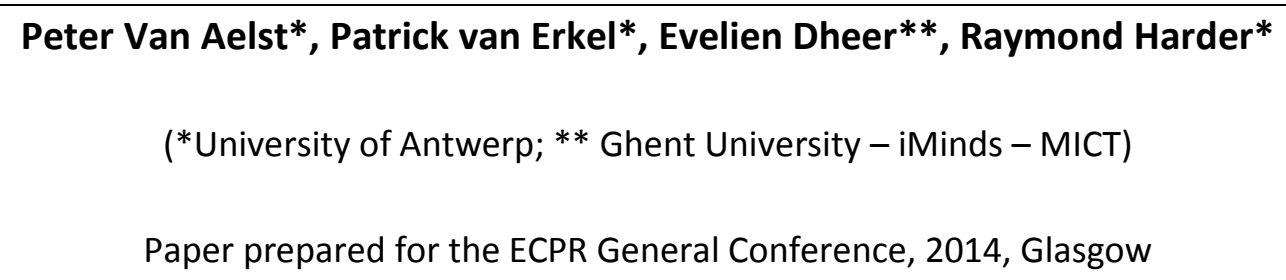

\title{
Who is leading the campaign charts? Comparing individual popularity on old and new media
}

\section{Introduction}

Traditionally, election campaigns are won in the mass media. Candidates that can attract plenty of journalistic attention and appear most on television and in newspapers are mostly also those that perform well on Election Day. Candidates' best bet, then, always used to be to aim for getting attention through these mass media outlets. The central query of this paper is whether this knowledge still holds to this day, when social media outlets are becoming ever more popular. Are candidates who are more active on social media also the ones that lead the traditional media charts? Or do we witness rather a tradeoff, in which candidates that invest more in digital campaigning are less prominent in the mass media? Finally, we are also interested in the electoral effect of social media. Does being active and successful on Twitter lead to more preferential votes for candidates? We test these conflicting hypotheses using data from the 2014 Belgian election campaign. We compare the attention of a large number of individual candidate gets in the traditional news media (represented here by newspapers) to their popularity, activities and impact on Twitter. In this way, we pair Twitter data with traditional media data, hence, take a "multi-platform" approach. In doing so, we meet one of the current shortcomings of social media research, which is precisely the lack of understanding of the multi-media ecology of information flows (Tufekci, 2014).

First we will discuss the recent literature on the role of old and new media in (personal) election campaigns. Since, the relationship between traditional mass media and social media has seldom been studied we formulate research questions instead of hypotheses. Next, we will present our research design and the main results. Our studies shows that being successful in newspaper and on twitter is strongly, but far from perfectly, correlated. This means that most candidates that score high on mass media attention are also more popular and successful in reaching out via Twitter. At the 
same time we see that being very active on Twitter does not improve your media visibility. We will elaborate on these findings in the discussion section and suggest pathways for further research.

\section{Theory and Research Questions}

Because of their potential impact on knowledge, attitudes, and behaviour of voters, election campaigns are a central topic of research in political communication. In particular, the role of the mass media has always been a prominent aspect of these studies. The media are generally considered as a key arena to reach out to voters and improve electoral support (e.g., Druckman, 2005; Holbrook, 1996; Hopmann, Vliegenthart, De Vreese, \& Albæk, 2010; Norris, Curtice, Sanders, Scammell, \& Semetko, 1999). During the last fifteen years the so-called new or digital media have gradually been included in theoretical models of campaigning (Norris, 2002; Foot \& Schneider, 2006; Gibson \& Cantijoch, 2011). Websites, blogs and email offer parties and candidates new opportunities to reach out and interact with voters. More recently, the scholarly attention shifted to the so-called social media or web campaigning 2.0 (Gibson, Römmele, \& Williamson, 2014; Lilleker et al., 2011).

Fueled by the success of Obama's 2008 social media campaign, the advent of social media was greeted with optimism (Harfoush, 2009). Gurus and media experts alike speculated that social media could be game-changers for modern day politics, influencing the dynamics of election campaigns. They would be facilitators of a more level playing field - effectively removing the barriers between political candidates and the electorate, making it possible for a broader range of political groups and candidates to attract and address their own audiences directly. Numerous empirical studies on social media and politics, however, suggest a more nuanced vision is necessary (e.g. Graham, Broersma, Hazelhoff, \& van 't Haar, 2013; Vergeer, Hermans, \& Sams, 2011). Direct interaction between politicians and citizens remains limited and overall it seems that virtual spheres mirror existing social structures. In other words, well-established actors (politicians holding seats or office, parties in government), tend to dominate digital arenas for political communication, thereby eroding the idea of a more level playing field. However, not all positivity about the effects of the use of social media in politics is unwarranted. For example, research has shown that Twitter can be an impact factor in how people vote (Gibson \& McAllister, 2014; Jacobs \& Spierings, 2014; Kruikemeier, 2014). In this way, the social network offers some counter-balance to the role of traditional mass media, which provide mainly access to already-powerful actors (Tresch, 2009; Sellers \& Schaffner, 2007).

As the use of social media is ever-increasing we can question whether political campaign teams now shift their focus from traditional mass media to social media. However, despite the ascribed positive qualities of social media and the empirical confirmation of some of these in other countries, their employment in a small country such as Belgium seems rather limited, as some empirical and 
anecdotal evidence suggests (Van Lier, 2013). It is obvious that social media do not function in isolation but in a wider media environment, something which is not always respected in research designs. To gain more insight into the interwoven nature of both types, we juxtapose social media data to traditional media data and consider them together. We ask if social media use in politics is still limited in the most recent election campaign and relate this to the visibility of politicians in traditional mass media.

RQ1: How do politicians' Twitter popularity and use compare to their presence in newspaper coverage?

Networking technologies allow for "politics of non-representation", as communication with the electorate can occur un-mediated by traditional media (Fenton, 2012). In this respect, we can argue that politicians are more autonomous in their means for communication, which in turn can be translated in political autonomy. However, empirical material seems in favor of the 'normalization hypothesis' which entails that powerful political actors offline dominate the discourse on Twitter (Jungherr, 2014). Nonetheless, exceptions have been found, which provide alternative evidence for the role of Twitter and its impact on the political debate. In Germany for example, the "nonconventional" Pirate Party obtained a sustainable position in the debate on social media (Jungherr, Jürgens, \& Schoen, 2012). In a similar manner, in the Netherlands, candidates of opposition parties were somewhat more active on Twitter and had a larger follower base (Vergeer, et al., 2011). In addition, for Facebook, the number of supporters has been found to relate to electoral success (Williams \& Gulati, 2008). Overall, it is argued that for minor parties or "non-conventional" political groups, social media platforms play an indispensable role in the process of political communication. Alongside communication with the electorate, these platforms provide a means to reach journalists and get mainstream media coverage. Broersma and Graham (2012) indicate that the use of Twitter allows politicians to influence the traditional media agenda. However, this has not yet led to an inclusion of more voices in the debate, as they found that newspapers cite a small number of politicians repeatedly, whereas others rarely get any attention.

RQ2: Does Twitter flatten the political landscape, providing opportunities for nonmainstream/lesser known candidates?

Twitter's dependence on traditional media is widely acknowledged. In particular, Twitter is studied as a "refraction chamber" (Rieder, 2012) as it alters existing news and information flows. In a similar manner, Twitter is understood as a "backchannel" (e.g. Kalsnes, Krumsvik, \& Storsul, 2014) because 
the volume and content of Twitter messages follow media events, and televised debates in particular. More specifically, research found that politicians comment news and issues discussed in traditional media (Enli \& Skogerb $\varnothing$, 2013) or respond to criticism uttered in traditional news outlets. In this respect, the platform is understood as "reactive" to mainstream media content and flows, rather than an "alternative" to the existing communication channels. Nonetheless, the vast majority of the studies on political uses of Twitter (and campaigns in particular) focus on one platform, i.e. Twitter and more specifically the content of the messages and the use of the Twitter conventions such as @replies (Graham, Jackson, \& Broersma, 2014; Jungherr, 2014). In this study, we move beyond the single focus on either traditional mass media or new social media and focus on how both relate to one another.

RQ3: How are media attention, Twitter use, and Twitter impact interconnected?

Assessing the interrelatedness of attention and impact within the media ecology is one thing, but ultimately it is about making an impact in the 'real world'. Political candidates aim for votes, not retweets. It has been established that visibility on traditional media has a positive impact on the electoral success of politicians. For instance, Van Aelst and colleagues showed that attention on television and newspapers contributed to the number of preferential votes candidates received in the 2003 Belgian election (Van Aelst, Maddens, Noppe, \& Fiers, 2008). Empirical analyses of election campaigns show that the use of Twitter could have the same effect, albeit more limited and only when certain conditions are met (Gibson \& McAllister, 2014; Kruikemeier, 2014; Spierings \& Jacobs, 2014). We examine here how these findings translate to the Belgian case, taking into account the politician's twitter popularity (followers), activity, and the impact of his/her tweets. By controlling for media attention we can study the additional impact of social media on preferential votes.

RQ4: How do popularity, activity and impact on Twitter affect the electoral success of a candidate?

\section{Research Design}

To study the relationship between the popularity of politicians in the old and the new media, we use a dataset which provides information on the behaviour of politicians on Twitter and their appearance in the newspapers for the May 2014 elections in Belgium. On 25 May, three elections were simultaneously held on different electoral levels (federal, regional, and European). We have opted to include all three levels, but restricted our research to the candidates that were electable in Flanders 
(the Dutch-speaking northern region of Belgium including $60 \%$ of the population).Twitter data collection is based on the open-source tool yourTwapperkeeper which is commonly used within social sciences (for a detailed overview of this tool, see Bruns \& Liang, 2012). For each Twitter user, an archive was set up which captured tweets from and to that particular user. ${ }^{1}$ As the Twitter API is the only entry point to the data, there is no base for comparison and therefore there are no guarantees for a comprehensive dataset (Highfield, Harrington, \& Bruns, 2013).

To calculate user statistics, we ran PHP scripts on each of the data archives which provide three different aspects of Twitter behaviour: popularity, activity and impact. Popularity is measured by the amount of followers a candidate had on 24 April 2014, the official start of the campaign. For activity we look at the number of tweets a candidate sent during the campaign (between April 24 and May 24). For this measure we also specify retweets and replies. Finally, to operationalize the impact of a politician on the social media, we construct a scale by adding the number of retweets, favorites and replies a candidate received (Cronbach's alpha $=.963$ ). The underlying assumption is that a tweet has a higher impact if it is retweeted more often or receives more favorites. These types of messages, e.g. replies and retweets, are recognized as parameters of influence in the debate (Ausserhofer \& Maireder, 2013).

To measure the prominence in the traditional media, we use the Belgian search engine Gopress. This engine contains all Belgian newspapers. For each candidate we counted the number of articles in which he or she was mentioned during the campaign (between April 24 and May 24). Each time we made an extra check whether the articles were indeed about the candidate and not about someone with a similar name. In our analysis, we included the eight paid Flemish newspapers ${ }^{2}$ and the free newspaper Metro.

Finally, we complement the Twitter and media data with official records about the candidate's age, gender, nationality, political mandate, position on the ballot list and his or her political party. We also include the number of preferential votes he or she received. In the Belgian (semi) open-list system voters can cast a preferential vote for multiple candidates on the same list. Because the candidates in our study participate in districts with different magnitudes and on different legislative levels, we divide the absolute number of preferential votes by the total number of votes in each district for the

\footnotetext{
${ }^{1}$ yourTwapperkeeper (Available at: http://github.com/jobrieniii/yourTwapperKeeper) is based on the Twitter streaming API, through which keywords can be "tracked". Aside the "track" parameter (which captures activity to a particular user), we also included the "follow" parameter to get Twitter activity from that particular user (For more information: https://dev.twitter.com/docs/streaming-apis/parameters\#follow).

${ }^{2}$ These newspapers are the broadsheets De Morgen, De Standaard and De Tijd, the popular papers Het Laatste Nieuws and Het Nieuwsblad, and the more regional oriented papers Het belang van Limburg, de krant van West-Vlaanderen and De Gazet van Antwerpen.
} 
type of election in which they run. This gives us the proportion of preferential votes for each candidate. Moreover, we take the log of this proportion, as the variable is skewed due to some outliers who receive the lump share of the votes. We also included dummies to indicate the type of elections in which the candidate participated (regional, national or European) and the district in which he or she was running. Table 1 shows the descriptives for these variables. In the end a total of 1520 (effective) candidates participated in the 2014 elections and we have data for 785 candidates. ${ }^{3}$

- Table 1 about here -

\section{Results}

Before we focus on the relationship between the coverage in the traditional media and the new social media, it is useful to first look at these platforms separately. Table 1 shows that when it comes to newspapers, political candidates appear on average in 7 news articles in the month before the elections. As expected the distribution of this variable is far from normal. Almost $56 \%$ of the candidates did not receive any attention from newspapers and of the other candidates $37 \%$ got covered in the news only to a limited extent. At the same time, Table 2 shows that a small group of politicians (about 4\%) were mentioned in more than 50 articles and received almost all the news attention. For example, Bart de Wever, party leader of the Flemish nationalists N-VA and winner of the elections, was mentioned in almost 800 articles during this period. Thus, traditional media only focus on a small group of politicians, while the large share of candidates receives only minimal or no coverage at all.

- Table 2 about here -

Whereas the traditional media only focus on the small group of the political elite, Twitter, in theory, could be a more egalitarian platform in which more (and lesser-known) candidates are able to reach their voters. However, table 3 shows, at least in Belgium, this seems hardly the case. Almost $64 \%$ of the politicians is inactive on Twitter, having no account or sending no tweets, while at the same time only a small group of politicians sent more than 100 tweets. More important is that if we focus only on the 324 candidates who were active, we still see strong differences in the impact of their tweets and on their amount of followers. Almost $44 \%$ of these candidates have less than 200 followers, while there is a small group of candidates (about 4\%) who have 10000 or more followers. The same

\footnotetext{
${ }^{3}$ In the Belgian system a distinction can be made between effective candidates and successors. Successors are candidates who cannot get elected for a seat directly, but who will receive a set if one of the effective candidates opts opt out or receives a political mandate. Since this distinction is hard to quantify, we only focus on the effective candidates in our analysis.
} 
skewed pattern emerges when we look at the impact of their tweets. $15 \%$ of the active candidates on Twitter received no retweets or favorites at all in the month before the election, and almost half of the candidates received less than 50 retweets. At the same time we see that $5 \%$ of the candidates were retweeted or received favorites more than 1000 times. Thus, while in theory Twitter offers a more egalitarian platform only a small number of politicians is successful in reaching their voters. This can to some extent be explained by the decision of many politicians not to use Twitter at all. Yet, even if we only focus on the active users we see the same pattern emerging.

-Table 3 about here-

Although newspaper attention is even more skewed in the direction of a small group of topcandidates, the distribution of twitter popularity among candidates shows a similar pattern. The question is, however, whether the small group of candidates that receives most of the newspaper attention is also the group with the most influence on Twitter. To get more insight in this relationship, table 4 ranks the 20 most popular politicians in the traditional media and on Twitter.

- Table 4 about here -

If we compare the top 20 of media popularity (newspaper attention) with the top 20 of twitter popularity (number of followers), we see a strong, but not perfect, similarity: 11 candidates appear in both lists. Moreover, when narrowing down to the top 10, we find that 6 politicians who are in the top 10 of media attention are also in the top 10 with the highest number of followers. Also, many candidates who only appear in one list still score high on the other variable ${ }^{4}$. The Top 20 of Twitter impact also shares a high resemblance with the lists of media attention and twitter popularity. 10 candidates in the top 20 of impact are also in the top 20 of media attention, while 12 candidates belong both to the 20 politicians with the most followers and the top 20 of politicians with the most impact.

If we, however, focus on Twitter activity we see large differences, as only 3 candidates in this list also appear in the top 20's of media attention and only 6 appear in the top 20 of Twitter impact. Most notably, the top 3 of most active candidates on Twitter during the campaign are fairly unknown politicians that were placed lower on the electoral list of their party and hardly received media attention. This higher degree of Twitter activity of these candidates seems to have reasonable impact in terms of retweets. For instance, the young candidate from the green party, Thomas Donceel, is not

\footnotetext{
${ }^{4}$ For example, Siegfried Bracke, who stands on the fourth position when it comes to followers, takes the $22^{\text {nd }}$ position on the media ranking list.
} 
only leading the twitter activity chart, he also is ranked third in terms of impact and eleventh in term of popularity. However, during the campaign he was not mentioned in a newspaper once.

While focusing on the top candidates is useful to get some first insights, we get a more systematic idea of the relationship between the traditional and the new media if we take all candidates into account. Therefore table 5 gives an overview of the correlations between the different measures. The matrix first of all confirms that media popularity strongly correlates with the popularity on Twitter: Candidates who appear more often in the newspaper also have more followers. The matrix also shows that media attention moderately correlates with the impact one has on Twitter. The correlation with activity is even slightly weaker, but still significant. These findings are in line with our conclusions based on the top 20. Only the relationship between Twitter activity and the other indicators seem to be a bit stronger if we include all candidates. Based on these results we can thus (preliminarily) conclude that most candidates who lead the traditional campaign charts are also doing good in the social media charts, but on the other hand that being active (and popular) on twitter does not guarantee attention in the mass media.

- Table 5 about here -

For a more stringent test on the relation between the traditional and the new media, we run a number of regressions with respectively media attention, Twitter activity and Twitter impact as dependent variables. Because the number of followers is measured by the start of the campaign (on April 24), before the other indicators - which are measured during the campaign - we do not estimate a model with followers as dependent variables. Also, in our models we only include the 324 candidates who were active on Twitter, as we cannot include measures for followers and Twitter impact for candidates without a Twitter account. ${ }^{5}$ Moreover, to account for the non-normal distribution of the different variables we take the natural log for all four indicators.

\section{- Table 6 about here -}

In model 1 (table 6) we regress media attention on the three different Twitter indicators. To a large extent this model confirms our previous findings. Candidates with more followers appear more often in newspapers, as do candidates with a stronger impact on Twitter. As there is a strong ambiguity about some of the causal relations, and since we do not have a longitudinal dataset, we cannot make any causal claims. Nevertheless, the regression does give evidence for a strong relation between media coverage on the one hand and a candidate's popularity on Twitter and the impact of his or her

\footnotetext{
${ }^{5}$ Giving these candidates a score of 0 would lead to a strong bias of the estimation.
} 
Tweets on the other. However, we should note that at the same time a candidate's activity on Twitter has a significant negative effect on traditional media coverage. Even though previously we found a significant correlation, once we control for the other indicators this relationship becomes negative. Apparently candidates who are popular in the traditional media feel less need to actively use Twitter. Or from the opposite perspective: candidates that have no access to the traditional media are more active on Twitter. This finding is confirmed in model 2 where the dependent variable is Twitter activity. The model confirms that candidates who are covered more often in the newspaper are less active on Twitter. At the same time, having more followers does lead to more activity.

Finally, in model 3 we look at the impact of the a candidate's tweets. This model first of all indicates that candidates who are more active on Twitter and who have more followers have a stronger impact with their tweets. On itself this is not surprising as these candidates have more tweets to be retweeted and more persons who can retweet them. More interesting is that we find a significant positive effect of media attention. Even if we control for the number of followers, candidates who receive a lot of media coverage are more likely to be retweeted or receive favorites. Thus, while these candidates might not necessarily be more active and send more tweets, the tweets they do send are likely to have a stronger impact than the tweets of candidates who are less popular in the traditional media. Note that we also control for position on the list, which is a good indicator of the political status of a candidate. This means that the positive relationship between media attention and twitter impact is more than a reflection of the political importance of a candidate. These findings give evidence that the politicians who lead the traditional campaign chart, are also the ones with the most influence on Twitter, even though they do not necessarily display more activity on this platform.

All three models contain several control variables. Most of these turn-out to be not significant. For instance, the differences between parties and types of elections are hardly relevant. A notable exception is age. Younger candidates have a lower visibility in the mass media, but are more active on Twitter and their tweets have a higher impact among their followers. This might suggest that the impact of social media will grow as these candidates obtain more prominent positions.

Finally, our fourth research question deals with the implications of this strengthening effect of Twitter and traditional media coverage when it comes to individual electoral success. Does success on one platform replace the other or do we see that both affect the number of preferential one receives, giving even more benefit to the most popular candidates? In model 4 (table 7) we run a model with the proportion of preferential votes $(\log )$ as dependent variable. In contrast to the previous models, the independent variables here precede the dependent variable in time (as votes 
were cast on May 25 and our Twitter and newspaper data are from April 24 - May 24). This allows for stronger causal claims. As expected, media attention has a significant positive effect on electoral success. This confirms earlier research that media has a positive effect on preferential votes on top of position on the list and the electoral success of the party (Van Aelst, et al., 2008). Interestingly, the model shows no significant effect of Twitter impact on electoral success. Nevertheless, there is a positive effect of the amount of followers. A larger share of followers leads to more preferential votes. Finally, activity has a negative effect on preferential voting. This is in line with the previous analyses that lesser-known candidates are most active on Twitter. Apparently for electoral success it's the amount of followers on Twitter which matter and not so much their Twitter activity or impact.

- Table 7 about here -

\section{Conclusion and discussion}

Over the years election campaigns have become more complex and multi-dimensional. New, mainly digital media, have entered the electoral arena, but the traditional media have maintained a central place in the campaign (Norris, 2002). Although campaign studies have devoted much attention to the use and effects of new social media, their relationship with the traditional media has remained largely unexplored. In this paper we tried to get a better idea of how old and new media go together by studying a large amount of individual candidates. Our study shows that candidates that have a prominent position in the media are generally also the ones with a large amount of followers on Twitter. Different types of analyses indicate that success in old and new media are clearly related. Furthermore, more media attention and more followers on Twitter leads to more preferential votes. However, the picture becomes more complex as we also look at Twitter activity and impact. Being active on Twitter does not lead to more news coverage and our multivariate analysis even suggest the relationship is negative. This can be interpreted in two ways. First, being active on Twitter does improve the newsworthiness of candidates. Second, for candidates that have no or very little media access Twitter might be a way to reach out to voters. However, the fact that Twitter activity does not contribute to electoral success tempers the expectations of this strategy. More important than being very active is getting reactions on Twitter. Candidates that are often retweeted are receiving more media attention, controlling for their number of followers and different political indicators. This suggests that also journalists follow the Twitter sphere closely and pick up candidates that make a difference. Again, Twitter impact does not lead directly to electoral success, but potentially indirectly via increased media attention. 
From the perspective of an ordinary candidate these results are not very encouraging. Campaigns are still run via the mass media were a limited number of candidates appear in the spotlights. This might explain why the majority of candidates is still not active on this social medium. Furthermore, the adoption of Twitter by the Dutch-speaking community in Belgium lags behind other social media platforms, such as Facebook (66\%), as only one fourth of the Flemish population has an account ${ }^{6}$. Hence, the results need to be understood in relation to the platform's limited adoption rate, which in turn is related to a particular socio-demographic use profile.

These results should of course treated with caution as this a first explorative study on the relationship between old and new media in a campaign context. Further research is needed to validate these findings in other countries and electoral systems and deepen our understanding of the mechanisms behind it. In particular, two streams of research seem necessary to develop further. First, we need to know more on how journalists use social media as a source of political information in their daily job and how activities of politicians influence their perceptions on the newsworthiness of these actors. Second, also looking more in-depth to those candidates and tweets that are successful in making it into the news could improve our understanding of the interrelatedness of traditional and new forms of political communication. This study at least showed that it is important to distinguish between different aspects of social media use by politicians.

\footnotetext{
${ }^{6}$ iMinds-iLab.o (2013) Digimeter Report 6. Adoption and usage of Media \& ICT in Flanders. Ghent: iMindsiLab.o.
} 


\section{References:}

Ausserhofer, J., \& Maireder, A. (2013). National politics on Twitter. Information, Communication \& Society, 16(3), 291-314.

Broersma, M., \& Graham, T. (2012). Social media as beat: Tweets as a news source during the 2010 British and Dutch elections. Journalism Practice, 6(3), 403-419. doi: 10.1080/17512786.2012.663626

Bruns, A., \& Liang, Y. E. (2012). Tools and mehtods for capturing Twitter data during natural disasters. First Monday, 17(4).

Druckman, J. (2005). Media Matter: How Newspapers and Television News Cover campaigns and Influence Voters. Political Communication, 22(4), 1041-1066.

Enli, G. S., \& Skogerb $\varnothing$, E. (2013). Personalized campaigns in party-centered politics: Twitter and Facebook as arenas for political communication. Information, Communication \& Society, 16(5), 757-774.

Fenton, N. (2012). The internet and social networking. In J. Curran, N. Fenton \& D. Freedman (Eds.), Misunderstanding the internet (pp. 123-148). New York: Routledge.

Foot, K., \& Schneider, S. (2006). Web Campaigning: MIT Press.

Gibson, R., \& Cantijoch, M. (2011). Comparing Online Elections in Australia and the UK: Did 2010 Finally Produce 'The' Internet Election? Communication, Politics and Culture, 44(2), 4-17.

Gibson, R., \& McAllister, I. (2014). Normalising or Equalising Party Competition? Assessing the Impact of the Web on Election Campaigning. Political Studies.

Gibson, R., Römmele, A., \& Williamson, A. (2014). Chasing the Digital Wave: International Perspectives on the Growth of Online Campaigning. Journal of Information Technology \& Politics, 11(2), 123-129.

Graham, T., Broersma, M., Hazelhoff, K., \& van 't Haar, G. (2013). Between Broadcasting Political Messages and Interacting with Voters. Information, Communication \&amp; Society, 16(5), 692-716. doi: 10.1080/1369118x.2013.785581

Graham, T., Jackson, D., \& Broersma, M. (2014). New platform, old habits? Candidates' use of Twitter during the 2010 British and Dutch general election campaigns. New Media \& Society, 1461444814546728.

Harfoush, R. (2009). Yes We Did! An inside look at how social media built the Obama brand: New Riders.

Highfield, T., Harrington, S., \& Bruns, A. (2013). Twitter as a technology for audiencing and fandom: The \#Eurovision phenomenon. Information, Communication \& Society, 16(3), 315-339. doi: 10.1080/1369118x.2012.756053

Holbrook, T. (1996). Do campaigns matter? Thousand Oaks: Sage Publications.

Hopmann, D. N., Vliegenthart, R., De Vreese, C., \& Albæk, E. (2010). Effects of Election News Coverage: How Visibility and Tone Influence Party Choice. Political Communication, 27(4), 389-405. doi: 10.1080/10584609.2010.516798

Jungherr, A. (2014). Twitter in Politics: A Comprehensive Literature Review. Rochester, NY: Social Science Research Network.

Jungherr, A., Jürgens, P., \& Schoen, H. (2012). Why the Pirate Party Won the German Election of 2009 or The Trouble With Predictions: A Response to Tumasjan, A., Sprenger, T. O., Sander, P. G., \& Welpe, I. M. "Predicting Elections With Twitter: What 140 Characters Reveal About Political Sentiment". Social Science Computer Review, 30(2), 229-234. doi: 10.1177/0894439311404119

Kalsnes, B., Krumsvik, A. H., \& Storsul, T. (2014, 2014). Social media as a political backchannel: Twitter use during televised election debates in Norway.

Kruikemeier, S. (2014). How political candidates use Twitter and the impact on votes. Computers in Human Behavior, 34, 131-139. 
Lilleker, D. G., Koc-Michalska, K., Schweitzer, E. J., Jacunski, M., Jackson, N., \& Vedel, T. (2011). Informing, engaging, mobilizing or interacting: Searching for a European model of web campaigning. European Journal of Communication, 26(3), 195-213.

Norris, P. (2002). Campaign communications. In L. LeDuc, R. Niemi \& P. Norris (Eds.), Comparing democracies 2. New challenges in the Study of Elections and Voting (pp. 127-147). London: Sage Publications.

Norris, P., Curtice, J., Sanders, D., Scammell, M., \& Semetko, H. A. (1999). On Message. Communicating the campaign. London: SAGE.

Rieder, B. (2012). The refraction chamber: Twitter as sphere and network. First Monday, 17(11), 170186.

Sellers, P. J., \& Schaffner, B. N. (2007). Winning coverage in the US Senate. Political Communication, 24, 377-391.

Spierings, N., \& Jacobs, K. (2014). Getting Personal? The Impact of Social Media on Preferential Voting. Political Behavior, 36(1), 215-234.

Tresch, A. (2009). Politicians in the media: Determinants of legislators' presence and prominence in Swiss newspapers. International Journal of Press/Politics, 14(1), 67-90.

Tufekci, Z. (2014, 2014). Big Questions for Social Media Big Data: Representativeness, Validity and Other Methodological Pitfalls. Paper presented at the Eight International AAAI Conference on Weblogs and Social Media.

Van Aelst, P., Maddens, B., Noppe, J., \& Fiers, S. (2008). Politicians in the news: media or party logic? Media attention and electoral success in the Belgian election campaign of 2003. European Journal of Communication, 23(2), 193-210.

Van Lier, R. (2013). Vlaamse politici op Twitter, een kwantitatief onderzoek naar het zendgedrag van Vlaamse politici op Twitter. Unpublished master's thesis, University of Antwerp, Antwerp.

Vergeer, M., Hermans, L., \& Sams, S. (2011). Online social networks and micro-blogging in political campaigning: The exploration of a new campaign tool and a new campaign style. Party Politics, 19(3), 477-501.

Williams, C., \& Gulati, G. (2008). What is a social network worth? Facebook and vote share in the 2008 presidential primaries. 
Table 1: Descriptive statistics of variables used in analysis

\begin{tabular}{|c|c|c|}
\hline Variable & Mean (S.E) & Freq (\%) \\
\hline Media attention & $6.77(41.3)$ & \\
\hline Activity on Twitter & $26.79(85.9)$ & \\
\hline Followers on Twitter & $1617.59(4501.1)$ & \\
\hline \multirow[t]{2}{*}{ Impact on Twitter } & $168.39(488.1)$ & \\
\hline & 8731.03(17061.3) & \\
\hline Age & $43.44(12.2)$ & \\
\hline \multicolumn{3}{|l|}{ Gender } \\
\hline - Male & & $431(54.9 \%)$ \\
\hline - Female & & $354(45.1 \%)$ \\
\hline \multicolumn{3}{|l|}{ Political mandate } \\
\hline - Yes & & $251(32.0 \%)$ \\
\hline$-\quad$ No & & $534(68.0 \%)$ \\
\hline \multicolumn{3}{|l|}{ Nationality } \\
\hline - Belgian or European & & 731(93.1\%) \\
\hline - Non-European & & $54(6.9 \%)$ \\
\hline \multicolumn{3}{|l|}{ Verkiezingstype } \\
\hline - Flemish & & $425(54.1 \%)$ \\
\hline - $\quad$ Federal & & $328(41.8 \%)$ \\
\hline - European & & $32(4.1 \%)$ \\
\hline \multicolumn{3}{|l|}{ Politieke partij } \\
\hline - N-VA & & $105(13.4 \%)$ \\
\hline$-\quad C D \& V$ & & $116(14.8 \%)$ \\
\hline - $\quad$ Groen & & $152(19.4 \%)$ \\
\hline - Sp.a & & $111(14.1 \%)$ \\
\hline$-\quad$ VB & & $71(9.0 \%)$ \\
\hline$-\quad$ VLD & & $107(13.6 \%)$ \\
\hline - $\quad$ PVDA & & $123(15.7 \%)$ \\
\hline
\end{tabular}

Table 2: Overview of media attention

\begin{tabular}{l|c} 
Number of articles & Frequency (\%) \\
\hline 0 & $55.5 \%$ \\
$1-10$ & $37.1 \%$ \\
$11-20$ & $2.8 \%$ \\
$21-50$ & $1.6 \%$ \\
$51-100$ & $1.7 \%$ \\
$>100$ & $1.3 \%$
\end{tabular}


Table 3: Overview activity, followers and impact on Twitter

\begin{tabular}{|ll|ll|ll|}
\hline $\begin{array}{l}\text { Number of } \\
\text { tweets send }\end{array}$ & Frequency (\%) & $\begin{array}{l}\text { Number of } \\
\text { followers }\end{array}$ & Frequency (\%) & $\begin{array}{l}\text { Number of } \\
\text { retweets }\end{array}$ & Frequency (\%) \\
\hline 0 & $63.6 \%$ & $0-100$ & $25.3 \%$ & 0 & $14.8 \%$ \\
\hline $1-10$ & $8.5 \%$ & $101-200$ & $18.2 \%$ & $1-50$ & $50.3 \%$ \\
\hline $11-20$ & $5.9 \%$ & $201-300$ & $9.9 \%$ & $51-100$ & $12.3 \%$ \\
\hline $21-30$ & $4.6 \%$ & $301-400$ & $8.6 \%$ & $101-150$ & $3.4 \%$ \\
\hline $31-40$ & $1.7 \%$ & $401-500$ & $4.9 \%$ & $151-200$ & $4.3 \%$ \\
\hline $41-50$ & $2.2 \%$ & $501-750$ & $6.2 \%$ & $201-300$ & $2.8 \%$ \\
\hline $51-60$ & $2.2 \%$ & $751-1000$ & $4.3 \%$ & $301-400$ & $3.1 \%$ \\
\hline $61-70$ & $1.8 \%$ & $1001-2500$ & $8.3 \%$ & $401-1000$ & $4.2 \%$ \\
\hline $71-100$ & $2.4 \%$ & $2501-5000$ & $6.2 \%$ & & $>1000$ \\
\hline $101-200$ & $4.2 \%$ & $5001-10000$ & $4.3 \%$ & & \\
\hline$>200$ & $3.2 \%$ & $>10000$ & $3.7 \%$ & & \\
\hline
\end{tabular}

Table 4: Overview of the top 20 in the media and on Twitter

\begin{tabular}{|c|c|c|c|c|}
\hline Place & Media attention & Popularity (followers) & $\begin{array}{l}\text { Activity (tweets } \\
\text { sent) }\end{array}$ & $\begin{array}{l}\text { Impact (retweets, } \\
\text { favorites and replies) }\end{array}$ \\
\hline 1 & Bart De Wever (798) & $\begin{array}{l}\text { Alexander de Croo } \\
\text { (47301) }\end{array}$ & $\begin{array}{l}\text { Thomas Donceel } \\
(1362)\end{array}$ & Bart De Wever (4885) \\
\hline 2 & Kris Peeters (641) & Kris Peeters (25971) & Maxime Penen (899) & Kris Peeters (3566) \\
\hline 3 & Hilde Crevits (238) & $\begin{array}{l}\text { Annemie Turtelboom } \\
(23805)\end{array}$ & Tom Potoms (731) & $\begin{array}{l}\text { Thomas Donceel } \\
\text { (3327) }\end{array}$ \\
\hline 4 & Wouter Beke (192) & $\begin{array}{l}\text { Siegfried Bracke } \\
(23160)\end{array}$ & Kris Peeters (572) & Kristof Calvo (2138) \\
\hline 5 & Geert Bourgeois (187) & $\begin{array}{l}\text { Freya van den Bossche } \\
\text { (22805) }\end{array}$ & Tanguy Veys (537) & Filip Dewinter (2040) \\
\hline 6 & Alexander de Croo (186) & Bart De Wever (21860) & $\begin{array}{l}\text { El Houari El Hannouti } \\
(423)\end{array}$ & $\begin{array}{l}\text { Annick de Ridder } \\
(1803)\end{array}$ \\
\hline 7 & Wouter van Besien (142) & Hilde Crevits (18507) & $\begin{array}{l}\text { Geert Bourgeois } \\
(410)\end{array}$ & $\begin{array}{l}\text { Freya Van den } \\
\text { Bossche (1715) }\end{array}$ \\
\hline 8 & $\begin{array}{l}\text { Annemie Turtelboom } \\
(137)\end{array}$ & Noël Slangen (17804) & Koen Geens (407) & $\begin{array}{l}\text { Peter Dedecker } \\
(1693)\end{array}$ \\
\hline 9 & Koen Geens (114) & Wouter Beke (14708) & $\begin{array}{l}\text { Erna Tindemans } \\
(400)\end{array}$ & Felix De Clerck (1369) \\
\hline 10 & Jo Vandeurzen (103) & John Crombez (13370) & Peter Cousaert (399) & Wouter Beke (1350) \\
\hline 11 & John Crombez (97) & $\begin{array}{l}\text { Thomas Donceel } \\
(13248)\end{array}$ & Felix de Clerck (395) & Hilde Crevits (1261) \\
\hline 12 & Peter Mertens (94) & Filip Dewinter (10052) & $\begin{array}{l}\text { Annick de Ridder } \\
(381)\end{array}$ & Theo Francken (1189) \\
\hline 13 & Joke Schauvliege (91) & $\begin{array}{l}\text { Mathias de Clercq } \\
(9408)\end{array}$ & Lies Corneillie (380) & $\begin{array}{l}\text { Alexander de Croo } \\
(1153)\end{array}$ \\
\hline 14 & Bart Somers (90) & Ingrid Lieten (9051) & Dirk Vansintjan (356) & $\begin{array}{l}\text { Siegfried Bracke } \\
(1115)\end{array}$ \\
\hline 15 & Filip Dewinter (78) & Patrick Dewael (8587) & Sofie Smets (336) & $\begin{array}{l}\text { Peter de Roove } \\
(1035)\end{array}$ \\
\hline 16 & Ingrid Lieten (74) & Kristof Calvo (8546) & Davy Buntinx (332) & Peter Mertens (977) \\
\hline 17 & Monica de Coninck (73) & $\begin{array}{l}\text { Joke Schauvliege } \\
\text { (7102) }\end{array}$ & Johan Pauly (303) & $\begin{array}{l}\text { Annemie Turtelboom } \\
\text { (965) }\end{array}$ \\
\hline 18 & Philippe Muyters (68) & Freya Piryns (6332) & Kristof Calvo (290) & Maxime Penen (951) \\
\hline 19 & Hendrik Bogaert (62) & Bart Tommelein (6254) & Kris Torfs (284) & Koen Geens (896) \\
\hline 20 & $\begin{array}{l}\text { Freya Van den Bossche } \\
\text { (60) }\end{array}$ & $\begin{array}{l}\text { Annick de Ridder } \\
\text { (5911) }\end{array}$ & Jo Vandeurzen (283) & $\begin{array}{l}\text { Wouter van Besien } \\
\text { (869) }\end{array}$ \\
\hline
\end{tabular}


Table 5: Correlation matrix between media attention and twitter indicators

\begin{tabular}{l|llll} 
& Media-attention & Followers & Activity & Impact \\
\hline Media-attention & $1.00^{* *}$ & $.617^{* *}$ & $.363^{* *}$ & $.441^{* *}$ \\
Followers & & $1.00^{* *}$ & $.572^{* *}$ & $.762^{* *}$ \\
Activity & & $1.00^{* *}$ & $.851^{* *}$ \\
Impact & & & & $1.00^{* *}$ \\
$*$ significant at $\mathrm{p}<.05 * *$ significant at $\mathrm{p}<.0$ & & &
\end{tabular}

Table 6: OLS regressions with the logged media attention (model 1 ), logged Twitter activity (model2) and logged twitter impact (model 3 ) as dependent variables $(\mathrm{N}=324){ }^{7}$

\begin{tabular}{l|c|c|c} 
& $\begin{array}{c}\text { Media Attention } \\
\text { Model 1 } \\
\mathrm{b}(\mathrm{SE})\end{array}$ & $\begin{array}{c}\text { Twitter Activity } \\
\text { Model 2 } \\
\mathrm{b}(\mathrm{SE})\end{array}$ & $\begin{array}{c}\text { Twitter Impact } \\
\text { Model 3 } \\
\mathrm{b}(\mathrm{SE})\end{array}$ \\
\hline Media attention (log) & - & $-.171(.06)^{* *}$ & $.099(.04)^{* *}$ \\
Followers (log) & $.605(.09)^{* *}$ & $.885(.08)^{* *}$ & $.580(.05)^{* *}$ \\
Activity (log) & $-.322(.08)^{* *}$ & - & $.737(.03)^{* *}$ \\
Impact & $.244(.09)^{* *}$ & - & - \\
Male & $.258(.20)$ & $.160(.22)$ & $.194(.13)$ \\
Age & $.031(.01)^{* *}$ & $-.022(.01)^{*}$ & $-.020(.01)^{* *}$ \\
Non-European background & $-.226(.44)$ & $-.064(.48)$ & $-.539(.28)$ \\
Political mandate & $.341(.22)$ & $-.533(.24)^{*}$ & $-.024(.14)$ \\
List position & $-.061(.01)^{* *}$ & $-.021(.02)$ & $-.011(.01)$ \\
Political party (Ref.=CD\&V) & & & \\
$\quad-\quad \mathrm{N}-$ VA & $-.483(.32)$ & $-.115(.34)$ & $.634(.20)^{* *}$ \\
$\quad-\quad$ Groen & $-.566(.33)$ & $-.359(.36)$ & $.037(.21)$ \\
$\quad-\quad$ Sp.a & $-.048(.34)$ & $-.716(.37)$ & $.208(.22)$ \\
$\quad-\quad$ Vlaams Belang & $-.794(.45)$ & $-.535(.49)$ & $.381(.29)$ \\
$\quad-\quad$ VLD & $-.175(.33)$ & $-.378(.36)$ & $-.102(.21)$ \\
$\quad-\quad$ PVDA & $-.918(.51)$ & $-1.365(.56)^{*}$ & $.335(.31)$ \\
Election (ref = Flemish) & & & \\
$\quad-\quad$ Federal & $-.151(.19)$ & $-.095(.21)$ & $.290(.12)^{*}$ \\
$\quad-\quad$ European & $.169(.61)$ & $.980(.67)$ & $.299(.39)$ \\
Constant & $-3.727(.62)^{* *}$ & $1.573(.68)$ & $-2.243(.40)^{*}$ \\
\hline $\mathrm{R}^{2} \quad$ & .481 & .370 & .855 \\
& & &
\end{tabular}

* significant at $\mathrm{p}<.05 * *$ significant at $\mathrm{p}<.01$

${ }^{7}$ We do not include impact in this model as it makes no sense causally that impact is placed before activity. 
Table 7: OLS regression with the logged proportion of preferential votes as dependent variable ( $N=324)$.

\begin{tabular}{|c|c|}
\hline & $\begin{array}{c}\text { Model } 4 \\
\text { b(SE) }\end{array}$ \\
\hline Media attention(log) & $.103(.02)^{* *}$ \\
\hline Followers (log) & $.152(.03)^{* *}$ \\
\hline Activity (log) & $-.057(.02)^{* *}$ \\
\hline Impact (log) & $.034(.02)$ \\
\hline Male & $-.230(.05)^{* *}$ \\
\hline Age & $.009(.00)^{* *}$ \\
\hline Non-European background & $.153(.12)$ \\
\hline Political mandate & $.150(.06)^{*}$ \\
\hline List position & $-.048(.00)^{* *}$ \\
\hline \multicolumn{2}{|l|}{ Political party $($ Ref. $=C D \& V)$} \\
\hline a N-VA & $.293(.08)^{* *}$ \\
\hline - Groen & $-.862(.09)^{* *}$ \\
\hline a Sp.a & $-.596(.09)^{* *}$ \\
\hline - Vlaams Belang & $-1.270(.12)^{* *}$ \\
\hline$-\quad$ VLD & $-.256(.09)^{* *}$ \\
\hline - PVDA & $-1.450(.13)^{* *}$ \\
\hline \multicolumn{2}{|l|}{ Election (ref = Flemish) } \\
\hline - Federal & $.228(.05)^{* *}$ \\
\hline - European & $.128(.16)$ \\
\hline Constant & $-5.631(.17)$ \\
\hline $\mathrm{R}^{2}$ & .837 \\
\hline
\end{tabular}

${ }^{*}$ significant at $\mathrm{p}<.05 * *$ significant at $\mathrm{p}<.01$ 